\title{
Clotrimazole used as antibacterial instead of antimycotic in two cases of Gilbert's Pityriasis rosea in association with allantoin and panthenol.
}

\author{
Texia-Research-Eu;Lorenzo Martini \\ Texia Research (turin); Department of Pharmaceutical Biotechnologies. University of Siena
}

\begin{abstract}
Since Pityriasis rosea has often been linked to upper tract respiratory infections and an increased incidence is reported among groups with close physical contact (eg, families, students, and military personnel), since ampicillin increases the distribution of the eruption, an effect bearing a striking resemblance to the drug's effect on the rash of some types of infections and substantially $P R$ occurs often in co-presence with Acne vulgaris (that is characterised besides of inflammatory factors from the presence and activity of the commensal bacteria Propionibacterium acnes, I have attempted to combat radically two important cases of $P R$ (Vidal's circinata and Hardy's disseminate and urticata), employing clotrimazole at very low concentrations, as this drug is able to substantivate to skin keratin and act as a drastic antibiotic against Gram +.
\end{abstract}

Keywords: Gilbert's Pityriasis rosea, Vidal's PR circinata, Hardy's PR disseminata ,clotrimazole, panthenol,

\section{Background}

Pityriasis rosea (PR) is a benign rash first described by Gilbert in 1860; the name means "fine pink scale." It is a common skin disorder observed in otherwise healthy people, most frequently in young adults. Other types of similar skin eruptions include lichen planus and psoriasis, but they must not be confused at all and a long list of investigations to determine the different types of diseases is available.PR is very common in the general population, and most cases occur in the spring and winter in temperate climates.

PR manifests as an acute, self-limiting, papulosquamous eruption with a duration of 6-8 weeks. It evolves rapidly, usually beginning with patch that heralds the eruption, the so-called "herald patch". It may sometimes occur in atypical variants or may mimic other skin disorders, such as tinea corporis and secondary syphilis. $(1,2,3)$ As a rule, PR requires only symptomatic treatment. Albeit an infectious etiology for PR has been sought for many years, it has been suggested that the condition could precipitated by a viral agent. Accordingly, a number of viruses have been studied with a view to determining whether they are linked to PR, but successes of the aforesaid researches were discontinuous and not determinant as well.

And so if PR has often been considered to be a viral exanthem, a view supported by the condition's seasonal occurrence, its clinical course, the possibility of epidemic occurrence, the presence of occasional prodromal symptoms, and the low rate of recurrence can induce to deem other etiologic causes, as inflammation and/or bacterial infection. Some AA indeed refer that oxidative stress may play a role too. (4)

Effectively, it is compulsory to suggest that PR has often been linked to upper tract respiratory infections An increased incidence is reported among groups with close physical contact (eg, families, students, and military personnel), though the condition does not appear to be highly contagious. A higher incidence of PR is also noted among patients with decreased immunity (eg, pregnant women and bone marrow transplant recipients). Moreover, ampicillin increases the distribution of the eruption, an effect bearing a striking resemblance to the drug's effect on the rash of infectious mononucleosis.This suggests that the very first prejudice that PR was to be reputed a viral exanthema may be corrected by the assumption that multi factorial causes (especially yeasts or bacterial insurgence) can be considered the real causes of PR.

In effect PR occurs often in co-presence with seborrheic dermatitis (that is a is a common, chronic inflammatory skin disorder, generally confined to areas where sebaceous glands are most prominent. Even if the condition is not harmful or contagious, it can be uncomfortable and unsightly, and involves blockage and/or inflammation of pilosebaceous units (hair follicles and their accompanying sebaceous gland) and can present as noninflammatory lesions. Even Acne vulgaris, e.g., has a multifactorial pathogenesis, of which the key factor could be genetics. (5) but it must be emphasized that acne develops as a result of an interplay of the following four chief factors:

(1) follicular epidermal hyperproliferation with subsequent plugging of the follicle,

(2) excess sebum production,

(3) inflammation. (6)

(4) but moreover and especially the presence and activity of the commensal bacteria Propionibacterium acnes, 
And, I tend to stress, seborrheic dermatitis and acne vulgaris are more common in patients with PR than in control subjects, and both malaises are always supported by bacteria Gram positive. Some investigators have suggested that a fungal infection is a more likely cause of PR than a viral infection is. However, no fungus has been isolated as a definite causal agent, even if manifold can be the fungi which act as commensal agents in the primary infection. Some AA (6) used to suggest a long treatment with erythromycin, and this confirms the sure attribution to infective etiology of the disease itself. It is noticeable that the main morbidity is from pigmentary changes, which may develop as lesions heal, especially in black people and these specific cases lesions are extremely hard to be cured. Both postinflammatory hyperpigmentation and hypopigmentation may occur. However, lesions do not result in scars. Bacterial super infections occur, when PR is not treated well and/or treatment is interrupted d'amblée.

The best treatment is to combat contemporarily Gram positive bacteria by the aids of antibiotics and treat eventual fungal super infections by the use of ample spectre antimycotics .

Kinds of PR are manifold, as the following:

Pityriasis invertita; typical in Asians or Mediterraneans naive to Aegeum Sea

Vidal's Pityriasis circinata: (papulae are similar to maculae and are enormous)

Pityriasis rosea urticata: always accompanied by strong itch

Horand's Pityriasis marginata

Bazin's Pityriasis rubra

Hardy's Pityriasis disseminata

And itch and fastidiuos sensation of low self esteem in social relationships are predominant in individuals suffering form all kind of these types of PR.

At the very beginning of XX century, the sole remedy was the treatment with sodium hyposulphite (5\%) and tartaric acid (10\%) solutions to be spread twice a day alternatively.

The former was indicated to struggle the bacterial component and the latter for the fungal component.

The restitutio ad integrum was achieved in 14 days of treatment.

Clotrimazole, (8) is primarily used locally in the treatment of vaginal and skin infections due to yeasts and dermatophytes. In vitro, it is most active against Candida spp., Trichophyton spp., Microsporum spp. and Malazzesia fuffur (Pityrosporon orbiculare). In addition, it has in vitro activity against certain Gram-positive bacteria, and at very high concentrations has activity against Trichomonas spp.

\section{Materials And Methods}

I have had the chance to recruit two cases of volunteers suffering of Pityriasis rosea:these cases were very peculiar, even because they were not able to define if they had felt the first herald patches before the full manifestation on trunk, legs and inguinal areas.

Case A was a woman $37 \mathrm{y}$. old, a cleaning lady unsatisfied from the detergents and cleaners she has to use everyday to clean the University where I work.

She presented a Vidal's PR circinata

Case B was a plumber, $44 \mathrm{y}$. old, he is smoker and does not disdain wine and liquors.

He used to talk always of itch on his back, so severe that did not permit to carry out, sometimes, his own mansions. He presented a severe Hardy's PR disseminate (and urticata) I have available for this scope a fluid and vanishing lypophlic gélée composed of clotrimazole (1\%), menthyl lactate (at low dosages to exorcise itch) panthenol (3\%, that reduces the degranulation of mastzellen and so the subsequent release of pruritus mediators) and allantoin, to avoid the formation of scars and lesions because of scratching.

Excipients are all synthetic anallergic esters and natural oils to maintain a calming effect on the damaged skin of the individuals. The relevant idea of this formulation is the usage of clotrimazole, at low dosage, $(1 \%)$ in order to combat the Gram positive bacteria assaulting the subjects who willingly underwent to my study.It remains unclear in both cases which is the main component that can be considered to play the causative role in the manifestation of the PR, but the important is that after two weeks of application of this lipophilic lotion, all papulae and maculae disappeared. Itch remained in all the cases a vanishing sensation of memoires.Generally clotrimazole (10\%) is used in paste or pomade for vaginal use or in shampooing products: the novelty of this invention is that the volunteers had to spread continuously the gélée onto their body, almost 6 times pro day.

Clotrimazole is highly substantive to skin keratin and this is my "Trojan horse", even if the subjet washes himself or sweats abundantly during the day job, clotrimazole adheres to skin for all the time of treatment, and for, it can perform absolutely its antibacterial property. (9) I have chosen these two volunteers cause the maculae could be measured encircling those by the use of a biological marker and scoring the measure or the area day after day, during its surface decrease.

The surface area was scored in mil (corresponding to $25,4 \mu \mathrm{m}$ ) and the decrements of the two individuals were plotted in Table I. 
Table I: the decreasing of surface area of papulae and maculae, day after day.

\begin{tabular}{|l|l|l|l|l|l|l|l|l|l|l|l|l|l|l|}
\hline Case & $\begin{array}{l}1^{\text {st }} \\
\text { day }\end{array}$ & $\begin{array}{l}2^{\text {nd }} \\
\text { day }\end{array}$ & $\begin{array}{l}3^{\text {rd }} \\
\text { day }\end{array}$ & $\begin{array}{l}4^{\text {th }} \\
\text { day }\end{array}$ & $\begin{array}{l}5^{\text {th }} \\
\text { day }\end{array}$ & $\begin{array}{l}6^{\text {th }} \\
\text { day }\end{array}$ & $\begin{array}{l}7^{\text {th }} \\
\text { day }\end{array}$ & $\begin{array}{l}8^{\text {th }} \\
\text { day }\end{array}$ & $\begin{array}{l}9^{\text {th }} \\
\text { day }\end{array}$ & $\begin{array}{l}10^{\text {th }} \\
\text { day }\end{array}$ & $\begin{array}{l}11^{\text {th }} \\
\text { day }\end{array}$ & $\begin{array}{l}12^{\text {th }} \\
\text { day }\end{array}$ & $\begin{array}{l}13^{\text {th }} \\
\text { day }\end{array}$ & $\begin{array}{l}14^{\text {th }} \\
\text { day }\end{array}$ \\
\hline A & 158 & 133 & 121 & 110 & 89 & 85 & 78 & 65 & 45 & 44 & 39 & 31 & 23 & 19 \\
\hline B & 208 & 199 & 178 & 167 & 145 & 132 & 111 & 98 & 96 & 85 & 63 & 44 & 31 & 25 \\
\hline
\end{tabular}

\section{Results}

In both cases the lowering of the borders of the papulae and maculae is $87.08 \%$ and $87.09 \%$.

Colour of the maculae grow progressively clear, almost till the complete achieving of the original colour of the skin that surround the papulae and maculae themselves. Both volunteers declare that sensation of itch fully disappears after 5-6 ${ }^{\text {th }}$ day and self esteem augments in each case, especially in the spots where maculae or papulae were visible and could not be hidden under clothes and habiliment.

\section{Conclusion}

It is very interesting to clarify that the usage of this lipophilic gélée has been providential and almost thaumaturgic.After three weeks from the last application, no papula or macula were present anymore.Itch seemed to disappear totally.

\section{Aknowledgements}

I have had the possibility or carrying out this study only owing to a commercial Italian product, that Texia Research, famous firm in Turin, has supplied generously to me for these specific purposes.

\section{References}

[1]. Rapini RP, Bolognia JL.; Jorizzo JL. (2007). Dermatology: 2-Volume Set. St. Louis: Ed. Mos

[2]. "Pityriasis rosea". American Osteopathic College of Dermatology. Retrieved 26 Jan 2010

[3]. Freedberg; et al. (2003). Fitzpatrick's Dermatology in General Medicine (6th ed.). McGraw-Hill. p. 445.

[4]. Habif, TP; (2004). Clinical Dermatology: A Clinical Guide to Diagnosis and Therapy (4th ed.). Mosby. pp. 246-8

[5]. Shalita AR, James Q, Rosso D, Webster GF; American Acne \& Rosacea Society., Acne vulgaris; Informa healthcare, 2011.

[6]. Zouboulis CC, Katsambas AD, Kligman AM; Pathogenesis and Treatment of Acne and Rosacea, Springer-Verlag, 2014.

[7]. Sharma PK, Yadav TP, Gautam RK, Taneja N, Satyanarayana L (2000). "Erythromycin in pityriasis rosea: A double-blind, placebocontrolled clinical trial". Journal of the American Academy of Dermatology 42 (2 Pt 1): 241-4.

[8]. American Society of Health-System Pharmacists, Inc. "Clotrimazole". NIH. Retrieved 19 April 2014.

[9]. Sawyer PR, Brogden RN, Pinder RM, Speight TM; Clotrimazole: a review of its antifungal activity and therapeutic efficacy:Drugs; 1975;9(6):424-47. 